\title{
MicroRNA Regulatory Networks Provide Feedback Mechanisms for Steroid Receptor Signaling
}

\section{Qun Zhou* and Gabriel Eades}

Department of Biochemistry and Molecular Biology, University of Maryland School of Medicine, Baltimore, MD 2120, USA

MicroRNAs (miRs) are short non-coding RNA molecules approximately 22-nucleotides in length that regulate gene expression through imperfect base pairing with target mRNA transcripts [1]. Primary transcripts of miRs (primiRs) are transcribed by RNA Polymerase II and are encoded within independent transcriptional units or within introns of protein-coding genes. Canonical miR processing begins in the nucleus where the RNase III endonuclease Drosha and DGCR8 protein complexes process miRs into stem-loop (pre-miR) molecules of approximately 70-nucleotides [1]. MiRs are exported from the nucleus to the cytoplasm by Exportin 5 proteins which recognize dsRNA, and upon reaching the cytoplasm, miRs are processed by another RNase III endonuclease, Dicer, finally resulting in a 22 -nucleotide miR duplex [2]. The mature or guide strand of this miR duplex then forms a complex with Argonaute proteins generating the RNA induced silencing complex (RISC) [2]. Once formed, this complex primarily targets the $3^{\prime}$ un-translated region (3'UTR) and to a lesser extent the coding region or 5'UTR [3-5] of target mRNAs and results in inhibition of gene expression by cleavage of target mRNAs or inhibition of their translation [6]. Both steroid receptors (e.g., estrogen receptor, progesterone receptor) and co-regulatory proteins important in steroid receptor signaling are confirmed targets of miR regulation. Frequently, this miR-mediated regulation of steroid receptor signaling is a component of feedback mechanisms responsible for attenuating or fine-tuning steroid receptor signaling.

Estrogen receptor (ER) signaling is subject to extensive regulation by miR networks. ERa mRNA is directly targeted and repressed by multiple individual miRs including miR-206 [7], miR-221/222 [8], miR-22 [9], miR-18a/b [10], miR-145 [11], and let-7a/b/i [12]. In addition, the ER $\beta$ isoform is directly targeted and suppressed by miR-92 [13]. Many of these miRs that regulate ER are involved in coordinated feedback mechanisms as a component of ER activation. Several of these ER-regulating miRs are therefore found to be estrogen-inducible, including miR-18a [14] and let-7 [15], while others are instead subject to estrogen-mediated repression, including miR-206 [7], miR-221/222 [16], and miR-145 [17]. Further complicating the relationship between miR networks and ER signaling is that ERa has also been implicated in the regulation of miR maturation. ERa was shown to associate with Drosha complex and block processing of a subset of pri-miR transcripts [18]. In addition, estrogen signaling has been shown to modulate the expression of several miR-processing enzymes including Exportin 5 [19], Dicer [19], and Argonaute 2 proteins [20].

Progesterone receptor (PR) is also subject to $\mathrm{miR}$ regulation. PR mRNA is directly targeted by miR-181 and miR-26a [21]. These miRs are implicated in a feed-forward loop involving ER. PR is an estrogen inducible gene whereas both $\mathrm{miR}-181$ and $\mathrm{miR}-26 \mathrm{a}$ are estrogen-repressible genes [21]; therefore PR accumulates in response to estrogen through both transcriptional and post-transcriptional mechanisms. Another miR, miR-126-3p, is also reported to target and regulate PR mRNA [22].

MiRs are also involved in regulating other steroid receptors in addition to ER and PR. Androgen Receptor (AR) mRNA is subject to direct targeting and suppression by numerous miRs, including miR135b, miR-185, miR-297, miR-299-3p, miR-34a, miR-34c, miR-3713p, miR-421, miR-449a, miR-449b, miR-634, miR-654-5p, miR-9 [23], and let-7c [24]. Similarly, glucocorticoid receptor (GR) mRNA was found to be a direct target of miR-130b [25], miR-18, and miR-124a [26]. Likewise, vitamin D receptor (VDR) mRNA is subject to direct regulation by miR-125b [27]. From these reports, it is clear that miRs are heavily involved in regulating steroid receptor signaling.

Many coregulatory proteins important in steroid receptor signaling are also subject to miR-mediated regulation. Steroid receptor coactivator 1 (SRC-1) mRNA is a direct target for miR-206 repression [28]. In addition, the coactivator Amplified in Breast Cancer 1 (AIB1) mRNA is subject to regulation by miR-17-5p [29] and miR-20a [30]. MiR suppression of steroid receptor coregulatory genes may also be a component of negative feedback from steroid receptor signaling. Both miR-17-5p and miR-20a were reportedly shown to be estrogeninducible genes $[14,15]$.

In addition to being the target of miR-suppression, steroid receptor signaling is also involved in regulating the expression of miRs. As briefly mentioned before, miR-221/222 are estrogen-repressible miRs [16]. In response to estrogens, ERa binds directly to the miR-221/222 promoter and recruits the corepressors Nuclear Receptor Corepressor (N-CoR) and Silencing Mediator for Retinoid and Thyroid hormone receptors (SMRT) [16]. Similarly, AR has been shown to suppress miR221/222 expression [31]. Treatment of prostate cancer cell lines with the synthetic androgen R1881 resulted in down-regulation of miR221/222 expression and bioinformatics analysis identified putative AR binding elements in the miR-221/222 promoter [31]. In addition, AR signaling has been shown to induce oncogenic miR-21 expression in prostate cancer cells by directly binding to the miR-21 promoter [32]. Glucocorticoids were also found to regulate miRs; dexamethasone treatment was found to induce the pro-apoptotic miR-15/16 cluster in acute lymphoblastic leukemia cells [33]. Similarly, progesterone was found to regulate $\mathrm{miR}$ expression. Treatment of endometrial stromal cells with the synthetic progesterone, medroxyprogesterone acetate, resulted in down-regulation of miR-20a, miR-21, and miR26a [34]. Finally, vitamin D signaling has also been shown to alter miR expression. 1a,25-dihydroxyvitamin D3 treatment of colon cancer cells resulted in increased miR-22 expression, which was found to contribute to the growth suppressing properties of VDR signaling [35].

*Corresponding author: Qun Zhou, Department of Biochemistry and Molecula Biology, University of Maryland School of Medicine, Baltimore MD 21201, USA, Tel: 410-706-1615; Fax: 410-706-8297; E-Mail: qzhou@som.umaryland.edu

Received March 13, 2012; Accepted March 15, 2012; Published March 17, 2012

Citation: Zhou Q, Eades G (2012) MicroRNA Regulatory Networks Provide Feedback Mechanisms for Steroid Receptor Signaling. J Steroids Hormon Sci 3:e103. doi:10.4172/2157-7536.1000e103

Copyright: ( 2012 Zhou Q, et al. This is an open-access article distributed under the terms of the Creative Commons Attribution License, which permits unrestricted use, distribution, and reproduction in any medium, provided the original author and source are credited. 
It is clear that there is an important relationship between steroid receptor signaling and miR networks. Activation of steroid receptors may modulate miR expression through direct interactions with regulatory elements in $\mathrm{miR}$ gene promoters, through the actions of downstream target genes, or through modulation of miR biogenesis. In turn, miRs may regulate pathways critical for cellular response to steroid signaling or miRs may exert a regulatory effect on steroid receptors, coregulatory proteins, or steroid target genes. MiR networks are commonly involved in feedback/feed-forward loops that fine tune gene expression. It is likely that most steroid receptor signaling is robustly regulated through miR feedback pathways as has already been witnessed for estrogen receptor signaling. At an accelerated rate, research is revealing details of how steroid receptor signaling modulates miR networks and the important roles of these miRs in normal physiology and in hormone-related malignancies. Improved understanding of the connection between miRs and steroid signaling may reveal prognostic biomarkers or therapeutic targets for hormonerelated cancers and other hormone-related illnesses.

\section{References}

1. Kim VN (2005) MicroRNA biogenesis: coordinated cropping and dicing. Nat Rev Mol Cell Biol 6: 376-385.

2. Winter J, Jung S, Keller S, Gregory RI, Diederichs S (2009) Many roads to maturity: microRNA biogenesis pathways and their regulation. Nat Cell Biol 11: $228-234$

3. Rigoutsos I (2009) New Tricks for Animal MicroRNAs: Targeting of Amino Acid Coding Regions at Conserved and Nonconserved Sites. Cancer Res 69: 32453248 .

4. Forman JJ, Coller HA (2010) The code within the code: microRNAs target coding regions. Cell Cycle 9: 1533-1541.

5. Lytle JR, Yario TA, Steitz JA (2007) Target mRNAs are repressed as efficiently by microRNA-binding sites in the 5' UTR as in the 3' UTR. Proc Natl Acad Sci U S A 104: 9667-9672.

6. Valencia-Sanchez MA, Liu J, Hannon GJ, Parker R (2006) Control of translation and mRNA degradation by miRNAs and siRNAs. Genes Dev 20: 515-524.

7. Adams BD, Furneaux H, White BA (2007) The Micro-Ribonucleic Acid (miRNA) miR-206 Targets the Human Estrogen Receptor- $\alpha(E R \alpha)$ and Represses ERa Messenger RNA and Protein Expression in Breast Cancer Cell Lines. Mol Endocrinol 21: 1132-1147.

8. Zhao JJ, Lin J, Yang H, Kong W, He L, et al. (2008) MicroRNA-221/222 Negatively Regulates Estrogen Receptor $\alpha$ and Is Associated with Tamoxifen Resistance in Breast Cancer. J Biol Chem 283: 31079-31086.

9. Pandey DP, Picard D (2009) miR-22 Inhibits Estrogen Signaling by Directly Targeting the Estrogen Receptor a mRNA. Mol Cell Biol 29: 3783-3790.

10. Leivonen SK, Mäkelä R, Ostling $P$, Kohonen $P$, Haapa-Paananen $S$, et al. (2009) Protein lysate microarray analysis to identify microRNAs regulating estrogen receptor signaling in breast cancer cell lines. Oncogene 28: 39263936.

11. Spizzo R, Nicoloso MS, Lupini L, Lu Y, Fogarty J, et al. (2009) miR-145 participates with TP53 in a death-promoting regulatory loop and targets estrogen receptor-[alpha] in human breast cancer cells. Cell Death Differ 17 246-254.

12. Zhao Y, Deng C, Wang J, Xiao J, Gatalica Z, et al. (2011) Let-7 family miRNAs regulate estrogen receptor alpha signaling in estrogen receptor positive breast cancer. Breast Cancer Res Treat 127: 69-80.

13. Al-Nakhle H, Burns PA, Cummings M, Hanby AM, Hughes TA, et al. (2010) Estrogen Receptor $\beta$ Expression Is Regulated by miR-92 in Breast Cancer. Cancer Res 70: 4778-4784

14. Castellano L, Giamas G, Jacob J, Coombes RC, Lucchesi W, et al. (2009) The estrogen receptor- $\alpha$-induced microRNA signature regulates itself and its transcriptional response. Proc Natl Acad Sci USA 106: 15732-15737.

15. Bhat-Nakshatri P, Wang G, Collins NR, Thomson MJ, Geistlinger TR, et al. (2009) Estradiol-regulated microRNAs control estradiol response in breast cancer cells. Nucleic Acids Res 37: 4850-4861.
16. Di Leva G, Gasparini P, Piovan C, Ngankeu A, Garofalo M, et al. (2010) MicroRNA Cluster 221-222 and Estrogen Receptor alnteractions in Breas Cancer. J Natl Cancer Inst 102: 706-721.

17. Xu J, Zhou X, Wong C (2011) Genome-Wide Identification of Estrogen Receptor Alpha Regulated miRNAs Using Transcription Factor Binding Data. Bioinformatics - Trends and Methodologies.

18. Yamagata K, Fujiyama S, Ito S, Ueda T, Murata T, et al. (2009) Maturation of MicroRNA Is Hormonally Regulated by a Nuclear Receptor. Mol Cell 36: 340-347.

19. Nothnick WB, Healy C, Hong X (2010) Steroidal regulation of uterine miRNAs is associated with modulation of the miRNA biogenesis components Exportin-5 and Dicer1. Endocrine 37: 265-273.

20. Cheng C, Fu X, Alves P, Gerstein M (2009) mRNA expression profiles show differential regulatory effects of microRNAs between estrogen receptor-positive and estrogen receptor-negative breast cancer. Genome Biol 10: 90.

21. Maillot G, Lacroix-Triki M, Pierredon S, Gratadou L, Schmidt S, et al. (2009) Widespread Estrogen-Dependent Repression of microRNAs Involved in Breast Tumor Cell Growth. Cancer Res 69: 8332-8340.

22. Cui W, Li Q, Feng L, Ding W (2011) MiR-126-3p regulates progesterone receptors and involves development and lactation of mouse mammary gland Mol Cell Biochem 355: 17-25.

23. Östling P, Leivonen SK, Aakula A, Kohonen P, Mäkelä R, et al. (2011) Systematic Analysis of MicroRNAs Targeting the Androgen Receptor in Prostate Cancer Cells. Cancer Res 71: 1956-1967.

24. Nadiminty N, Tummala R, Lou W, Zhu Y, Zhang J, et al. (2012) MicroRNA let7c Suppresses Androgen Receptor Expression and Activity via Regulation of Myc Expression in Prostate Cancer Cells. J Biol Chem 287: 1527-1537.

25. Tessel MA, Benham AL, Krett NL, Rosen ST, Gunaratne PH (2011) Role for MicroRNAs in Regulating Glucocorticoid Response and Resistance in Multiple Myeloma. Horm Cancer 2: 182-189.

26. Vreugdenhil E, Verissimo CS, Mariman R, Kamphorst JT, Barbosa JS, et al (2009) MicroRNA 18 and 124a Down-Regulate the Glucocorticoid Receptor: Implications for Glucocorticoid Responsiveness in the Brain. Endocrinology 150: $2220-2228$

27. Mohri T, Nakajima M, Takagi S, Komagata S, Yokoi T (2009) MicroRNA regulates human vitamin D receptor. Int J Cancer 125: 1328-1333.

28. Adams BD, Cowee DM, White BA (2009) The Role of miR-206 in the Epiderma Growth Factor (EGF) Induced Repression of Estrogen Receptor- (ERalpha) Signaling and a Luminal Phenotype in MCF-7 Breast Cancer Cells. Mo Endocrinol 23: 1215-1230.

29. Hossain A, Kuo MT, Saunders GF (2006) Mir-17-5p Regulates Breast Cancer Cell Proliferation by Inhibiting Translation of AIB1 mRNA. Mol Cell Biol 26 8191-8201.

30. Yu Z, Wang C, Wang M, Li Z, Casimiro MC, et al. (2008) A cyclin D1/microRNA $17 / 20$ regulatory feedback loop in control of breast cancer cell proliferation. $J$ Cell Biol 182: 509-517.

31. Ambs S, Prueitt RL, Yi M, Hudson RS, Howe TM, Petrocca F, et al. (2008) Genomic Profiling of MicroRNA and Messenger RNA Reveals Deregulated MicroRNA Expression in Prostate Cancer. Cancer Res 68: 6162-6170.

32. Ribas J, Ni X, Haffner M, Wentzel EA, Salmasi AH, et al. (2009) miR-21: An Androgen Receptor-Regulated MicroRNA that Promotes Hormone-Dependent and Hormone-Independent Prostate Cancer Growth. Cancer Res 69: 7165 7169.

33. Rainer J, Ploner C, Jesacher S, Ploner A, Eduardoff M, et al. (2009) Glucocorticoid-regulated microRNAs and mirtrons in acute lymphoblastic leukemia. Leukemia 23: 746-752.

34. Pan Q, Luo X, Toloubeydokhti T, Chegini N (2007) The expression profile of micro-RNA in endometrium and endometriosis and the influence of ovarian steroids on their expression. Mol Hum Reprod 13: 797-806.

35. Alvarez-Díaz S, Valle N, Ferrer-Mayorga G, Lombardía L, Herrera M, et al. (2012) MicroRNA-22 is induced by vitamin D and contributes to its antiproliferative, antimigratory and gene regulatory effects in colon cancer cells. Hum Mol Genet. 